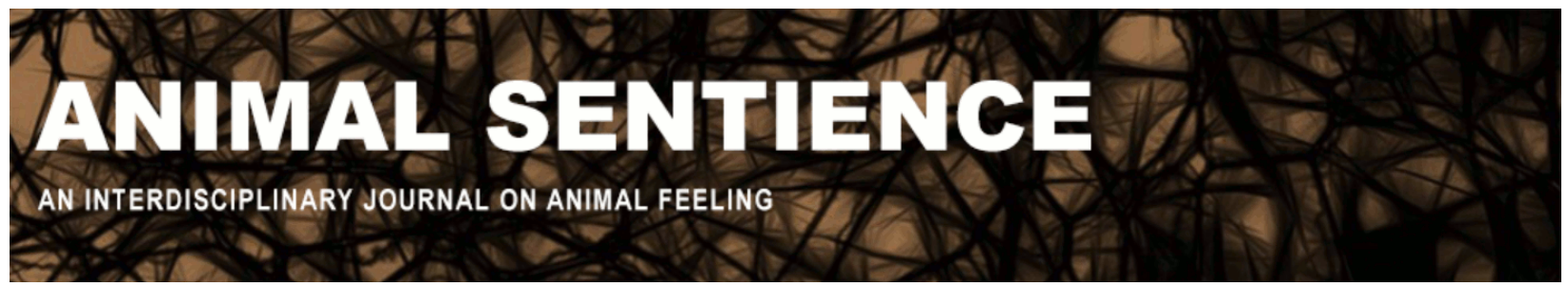

Pauketat, Janet VT (2020) A psychological perspective on elephant rewilding. Animal Sentience 28(4)

DOI: $10.51291 / 2377-7478.1559$

Date of submission: $2020-02-21$

Date of acceptance: 2020-02-26

(c)

This article has appeared in the journal Animal

Sentience, a peer-reviewed journal on animal

cognition and feeling. It has been made open access,

free for all, by WellBeing International and deposited

in the WBI Studies Repository. For more information,

please contact

wbisr-info@wellbeingintl.org.

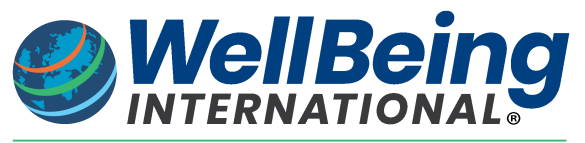

SOLUTIONS FOR PEOPLE, ANIMALS AND ENVIRONMENT 


\title{
A psychological perspective on elephant rewilding
}

Commentary on Baker \& Winkler on Elephant Rewilding

\author{
Janet VT Pauketat \\ Department of Psychology \\ Princeton University
}

\begin{abstract}
Baker \& Winkler describe the complexities of captive elephant conservation efforts in Thailand through multiple lenses. They advocate rewilding captive elephants within mixed elephant-human communities based on the benefits to captive elephants as well as to Karen mahout communities, given the entrenched economic and social systems in Thailand. From a psychological perspective, this advocacy is grounded in considerations of culture, cognition, speciesism, the differential valuing of others in social hierarchies, and the potential for positive interaction to build positive emotions and trust that enable successful rewilding in a world of elephants and humans.
\end{abstract}

Janet Pauketat is a postdoctoral research associate at Princeton University, Department of Psychology. She conducts research on the psychology of how socio-cultural contexts and emotion shape human behavior, on global citizenship and trust, and on the dynamics of collective emotions in social interactions. Website

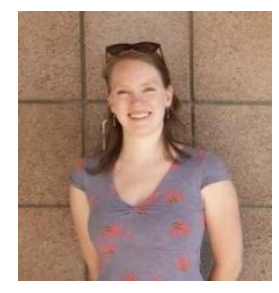

Depending on their interests and concerns, many will approach Baker \& Winkler's (B\&W's) (2020) target article on elephant rewilding from a perspective of either elephant or human primacy. $B \& W$ 's pragmatic approach places the needs of elephants, both free-living and captive, at the forefront, while attempting to accommodate the interactive relationship between elephants and humans in a world of tourism, globalized economics, and cultural traditions. B\&W's proposals touch on several psychological processes that might help explain the potential benefit of rewilding for elephants embedded in a human-controlled environment.

1. Culture, cognition, and interdependence. Human cultures vary in how much they perceive interconnections between themselves and others, and in how they perceive and think about the world around them (Hofstede, 2001; Markus \& Kitayama, 1991). To leverage conservation efforts for the benefit of all members of Elephas maximus, we need to pay attention to the psychological, social, and cultural interdependence between humans and elephants. B\&W describe how interdependent elephants and humans in Thailand are, especially in Karen mahout communities. This interdependence is economic and systemic but also psychological, with fewer and more permeable perceptual boundaries perceived between the self and others when there is greater psychological interdependence (Markus \& Kitayama, 1991). Thailand scores as a strongly interdependent nation. People care about preserving well-established norms, sustaining traditions, and avoiding threatening or ambiguous situations (Hofstede Insights, 2020; Hofstede, 2001). B\&W's proposal to engage mahouts in healthy rewilding aligns well with these cultural processes. 
Based on only part of the equation, considering only captive elephants or only mahouts would limit the effectiveness of any conservation effort for Asian elephants. To focus only on freeliving elephants rather than the whole elephant conservation context in Thailand would be another instance of this narrow human 'cognitive style' (Li \& Yap, 2016; Yama, 2018).

The 3R model (Rescue/Rehabilitate/Rewild) takes into account psychological and cultural processes in Thailand - at the national as well as the individual human decision-maker levels concerning where, when and how to initiate the rewilding of elephants. B\&W's awareness of the cultural and psychological complexities of national preferences and the interdependent relationships in Thailand grounds their conservation model, extending it even beyond the economic arguments likely to persuade policy makers and mahouts to support conservation. Separating captive elephants from humans is likely to violate these psychological processes, hence making it unlikely to improve the situation for elephants.

2. Social dominance theory and speciesism. B\&W point out some flaws in conservation efforts linked to human psychology that lead conservationists to ignore the approximately 15,000 captive Asian elephants in range countries. B\&W argue that all members of this species, captive and freeliving, need conservation efforts and protections. Valuing some groups over others to uphold social hierarchy is a powerful, well-established psychological propensity in humans called social dominance (Sidanius et al., 2017; Pratto, Sidanius, \& Levin, 2006). It is positively correlated with speciesism in which humans value some species over others (Caviola, Everett, \& Faber, 2019; Everett et al., 2019; Dhont, Hodson, \& Leite, 2016). Perhaps valuing free-living elephants over captive (human-dominated) elephants is a side-effect of this.

$\mathrm{B} \& \mathrm{~W}$ rightly point to how inequalities affect both humans and nonhumans. Psychological theory and research support this. The circumstances of captive elephants and vulnerable mahout communities in Thailand maintain the existing hierarchy of human and nonhuman groups. Why deny captive elephants the potential benefits of initiatives like the $3 R$ model of rescuing, rehabilitating, and rewilding? Why work against a model that aims to improve the lives of mahouts (who are undervalued in society) and also has the potential to improve the quality of life as well as to diversify the genetic pool of free-living elephants?

3. Positive interaction, emotion, and trust. Ideally, as B\&W emphasize, elephants would live wild and free again, alongside human society. B\&W acknowledge, however, that this outcome is unlikely given the economic, cultural, and social systems in Thailand. They discuss how rewilding endeavors recognize humans as part of the natural world and suggest that we focus our efforts more on rewilding elephants who have enduring relationships with humans. We know that both elephants and humans are highly social, emotionally complex, and cognitively adept species. Social interaction makes collective emotion possible; positive interactions build positive emotion, bonding, and trust (Lawler, Thye, \& Yoon, 2014; Frederickson, 2013; Carter \& Porges, 2011; Marková \& Gillespie, 2008). Elephant interactions with humans need not be damaging. Much of the psychological research on social emotion is based on human interactions; perhaps it is speciesism that prevents us from pursuing research and conservation agendas based on the longterm effects of positive interactions between captive elephants and humans. Increased interspecies trust may enable captive elephants to regain meaningful, autonomous lives from rewilding efforts based on positive interactions with mahouts. 


\section{References}

Baker, L., \& Winkler, R. (2020). Asian elephant rescue, rehabilitation and rewilding. Animal Sentience 28(1).

Carter, C.S., \& Porges, S.W. (2011). The neurobiology of social bonding and attachment. In J. Decety \& J.T. Cacioppo (Eds.), The Oxford Handbook of Social Neuroscience (p. 151-163). Oxford University Press.

Caviola, L., Everett, J.A.C., \& Faber, N.S. (2019). The moral standing of animals: Towards a psychology of speciesism. Journal of Personality and Social Psychology, 116(6): 1011-1029.

Dhont, K., Hodson, G., \& Leite, A.C. (2016). Common ideological roots of speciesism and generalized ethnic prejudice: The social dominance human-animal relations model (SDHARM). European Journal of Personality, 30: 507-522.

Everett, J.A.C., Caviola, L., Savulescu, J., \& Faber, N.S. (2019). Speciesism, generalized prejudice, and perceptions of prejudiced others. Group Processes \& Intergroup Relations, 22(6): 785803.

Frederickson, B. (2013). Positive emotions broaden and build. Advances in Experimental Social Psychology, 47: 1-53.

Hofstede Insights. (2020, February 17). Hofstede insights.

Hofstede, G. (2001). Cultures consequences: Comparing Values, Behaviors, Institutions, and Organizations Across Nations. Sage Publications.

Lawler, E.J., Thye, S.R., \& Yoon, J. (2014). The emergence of collective emotions in social exchange. In C. von Scheve \& M. Salmela (Eds.), Collective Emotions. Oxford Scholarship Online.

Li, J., \& Yap, S. (2016). Culture and cognition. Current Opinions in Psychology, 8: 105-111.

Marková, I., \& Gillespie, A. (Eds.). (2008). Trust and Distrust: Sociocultural Perspectives. Information Age Publishing, Inc.

Markus, H.R., \& Kitayama, S. (1991). Culture and the self: Implications for cognition, emotion, and motivation. Psychological Review, 98(2): 224-253.

Pratto, F., Sidanius, J., \& Levin, S. (2006). Social dominance theory and the dynamics of intergroup relations: Taking stock and looking forward. European Review of Social Psychology, 17: 271-320.

Sidanius, J., Cotterill, S., Sheehy-Skeffington, J., Kteily, N., \& Carvacho, H. (2017). Social dominance theory: Explorations in the psychology of oppression. In C.G. Sibley \& F.K. Barlow (Eds.), The Cambridge Handbook of the Psychology of Prejudice (pp. 149-187). Cambridge University Press.

Yama, H. (2018). Thinking and reasoning across cultures. In L.J. Bell \& V.A. Thompson (Eds.), The Routledge International Handbook of Thinking and Reasoning (pp. 624-638). Routledge. 


\section{Call for Papers}

Special Issue of the Journal of Consciousness Studies

Plant Sentience: Theoretical and Empirical Issues

Guest Editors: Vicente Raja (Rotman Institute of Philosophy, Western University) Miguel Segundo-Ortin (School of Liberal Arts, University of Wollongong)

In this special issue, we address the issue of plant sentience/consciousness from different disciplines that combine both theoretical and empirical perspectives. Some of the questions to be addressed in the special issue include the following:

- Plants exhibit interesting behaviors; does this entail that they are conscious to some extent?

- What are the requirements for a living organism to be conscious? Do plants meet these requirements?

- What does the possibility of plant sentience/consciousness entail for the study of the evolution of consciousness?

- Is it just a categorical mistake to attribute consciousness to plants?

- Can we talk about different levels or degrees of consciousness?

\section{How to submit?}

\section{Deadline: June 1st, 2020}

Please submit your papers (max. 9000 words including footnotes, references, abstract, etc.) to vgalian@uwo.ca with subject "Paper Special Issue JCS".

For more information, including bibliography and more detailed descriptions of the topics and questions to be addressed in the papers submitted to the special issue, please contact the guest editors atvgalian@uwo.ca (Vicente) or ms0693@uowmail.edu.au (Miguel). 